\title{
Overexpression of human telomerase reverse transcriptase C-terminal polypeptide sensitizes HeLa cells to 5-fluorouracil-induced growth inhibition and apoptosis
}

\author{
GUIMIAO LIN $^{1 *}$, QIANG CHEN ${ }^{1 *}$, SHUIHONG YU ${ }^{1}$, SUXIA LIN $^{1}$, HONG YAO $^{2}$, \\ ZHANGCHI DING ${ }^{1}$, SIPING CHEN ${ }^{1}$, MARIE CHIA-MI LIN ${ }^{1}$ and XIAOMEI WANG ${ }^{1,3}$
}

\begin{abstract}
${ }^{1}$ The Engineering Lab of Synthetic Biology and the Key Lab of Biomedical Engineering, School of Medicine, Shenzhen University, Shenzhen, Guangdong 518060; ${ }^{2}$ School of Biomedical Science and State Key Laboratory in Oncology in South China, Chinese University of Hong Kong, Shatin, Hong Kong 999077;

${ }^{3}$ Research Institute of Uropoiesis and Reproduction, School of Medicine, Shenzhen University, Shenzhen, Guangdong 518060, P.R. China
\end{abstract}

Received July 2, 2013; Accepted October 30, 2013

DOI: $10.3892 / \mathrm{mmr} .2013 .1777$

\begin{abstract}
Fluorouracil (5-FU) is a commonly used anti-tumor chemotherapeutic drug for cervical carcinoma. However, increased drug resistance may occur following several cycles of 5-FU-based chemotherapy. Novel strategies of gene therapy for enhancing the sensitivity of cancer cells to 5-FU chemotherapy have been intensively explored. Human telomerase reverse transcriptase (hTERT)C27 is a newly constructed hTERT C-terminal polypeptide that is capable of promoting chromosome end-to-end fusion during anaphase and inducing telomere dysfunction. In the present study, the effects of hTERTC27 overexpression on 5-FU-induced proliferation inhibition and apoptosis were observed. HeLa cells were cultured and transfected with the constructed pcDNA3.1 or pcDNA3.1-hTERTC27 vectors. Expression of hTERTC27 was detected using western blot analysis and was assessed using MTT assays and flow cytometry. The results demonstrated that overexpressed hTERTC27 increased the sensitivity of the HeLa cells to 5-FU and significantly inhibited HeLa cell proliferation with 5-FU treatment. In addition, hTERTC27 overexpression evidently promoted the 5-FU-induced apoptosis by increasing the expression of activated caspase- 3 and -9 and by downregulating the expression
\end{abstract}

Correspondence to: Professor Xiaomei Wang and Professor Marie Chia-Mi Lin, School of Medicine, Shenzhen University, 3688 Nanhai Avenue, Shenzhen, Guangdong 518060, P.R. China

E-mail: xmwang@szu.edu.cn

E-mail:mcllin@szu.edu.cn

*Contributed equally

Key words: hTERTC27, gene therapy, 5-fluorouracil, cervical carcinoma of B-cell lymphoma 2. The results suggest that hTERTC27 overexpression is a potential clinical strategy for enhancing the antitumor effect of 5-FU chemotherapy in the treatment of cervical carcinoma.

\section{Introduction}

Cervical carcinoma is one of the most frequent types of cancer encountered in women (1). Currently, 5-fluorouracil (5-FU), a commonly used antitumor chemotherapeutic drug, has been shown to be one of the standard chemoradiotherapy regimens in the treatment of many carcinomas including cervical cancer (2-4). However, tumor recurrence and metastasis occur in a large number of cancer patients mainly due to limited drug sensitivity and an increased drug resistance (5). Therefore, novel strategies of gene therapy for enhancing the sensitivity of cancer cells to drug-induced growth inhibition and apoptosis have been intensively explored (6-8).

Telomerase is an attractive molecular target for cancer gene therapy due to its high prevalence in tumor cells (9-11). Human telomerase is a ribonucleoprotein complex, which is composed of an RNA component hTR and telomerase reverse transcriptase (TERT), the catalytic protein subunit of telomerase (12). The enzyme TERT is critical for maintaining the telomere length and prolonging the life span of cells, thereby contributing to uncontrolled cell proliferation (10). Telomerase activity is markedly increased in the majority of tumors but not detected in the majority of normal cells. The reactivation of telomerase during carcinogenesis is a common hallmark in the majority of human tumors. In our previous study, hTERTC27, a $27 \mathrm{kDa}$ C-terminal polypeptide of hTERT, was reported to clearly decrease cell proliferation and inhibit the tumorigenicity of human cervical carcinoma and glioblastoma by promoting chromosome end-to-end fusion during anaphase and by inducing telomere dysfunction (13-16). However, hTERTC27 treatment alone may not be capable of achieving a long-term benefit for cancer therapy due to the unstable expression of this polypeptide, and the problem of therapeutic gene integrating 
into the genome of tumor cells with a rapidly dividing nature. However, it is noteworthy that ectopic overexpression of this polypeptide markedly enhances the sensitivity of HeLa cells to $\mathrm{H}_{2} \mathrm{O}_{2}$ treatment. Therefore, we hypothesized that hTERTC27 overexpression is a potentially effective strategy for sensitizing cervical tumor cells to chemotherapeutics and enhancing the antitumor effect of 5-FU chemotherapy.

To the best of our knowledge, the present is the first study to report the antitumor effects of 5-FU and overexpressed hTERTC27 on cervical carcinoma HeLa cells. Overexpressed hTERTC27 increased the sensitivity of the HeLa cells to 5-FU and significantly inhibited the HeLa cell proliferation with 5-FU treatment. In addition, hTERTC27 overexpression clearly promoted 5-FU-induced apoptosis by upregulating the expression of activated caspase- 3 and -9 , and downregulating the expression of B-cell lymphoma 2 (Bcl-2). These results indicate that overexpression of hTERTC27 may provide a novel approach for enhancing the sensitivity of 5-FU chemotherapy in the treatment of cervical carcinoma.

\section{Materials and methods}

Cell culture. Human cervical cancer HeLa cells were obtained from ATCC (Manassas, VA, USA) and maintained in Dulbecco's modified Eagle's medium (DMEM; Hyclone Laboratories, Inc., South Logan, UT, USA), supplemented with $10 \%$ fetal bovine serum (FBS; Hyclone Laboratories, Inc.), $100 \mu \mathrm{g} / \mathrm{ml}$ penicillin (Ameresco, Middletown, CT, USA) and $100 \mu \mathrm{g} / \mathrm{ml}$ streptomycin (Ameresco). The cells were cultured at $37^{\circ} \mathrm{C}$ in a humidified atmosphere with $5 \% \mathrm{CO}_{2}$.

Transfection. The pcDNA3.1-hTERTC27 plasmid was maintained in our laboratory. cDNAs of a $27 \mathrm{kDa}$ hTERT C-terminal polypeptide (hTERTC27, amino acid residues 882-1132) was constructed downstream. The HeLa cells were transfected with pcDNA3.1 vectors (known as control-HeLa cells) or pcDNA3.1-hTERTC27 vectors (termed C27-HeLa cells) using Lipofectamine 2000 transfection reagent (Invitrogen Life Technologies, Carlsbad, CA, USA) and following the manufacturer's instructions. The untransfected HeLa cells were designated as mock-HeLa cells. Twenty-four hours after transfection, the cells were treated with 5-FU and experiments were subsequently performed.

Western blot analysis. The expression of hTERTC27 was detected at 12, 24, 48 and $72 \mathrm{~h}$ after transfection. The expression of caspase-3, -9 and Bcl-2 was detected $48 \mathrm{~h}$ after 5-FU treatment. Western blot analysis was performed as described previously (17). Antibodies against the hTERT COOH-terminal fragment (1:250; Santa Cruz Biotechnology, Inc., Santa Cruz, CA, USA), cleaved caspase-3 $(1: 1,000)$ and cleaved caspase-9 (1:1,000; both Cell Signaling Technology, Inc., Danvers, MA, USA) and Bcl-2 (1:500; Santa Cruz Biotechnology, Inc.) were used. The bound antibodies were located by further incubation with horseradish peroxidase-conjugated goat anti-rabblit IgG (1:5,000; Santa Cruz Biotechnology, Inc.). $\beta$-actin (1:500; Santa Cruz Biotechnology, Inc.) was used as a loading control. Blots were developed with an ECL plus kit (Pierce Biotechnology, Inc., Rockford, IL, USA), and exposed to Kodak film (Eastman Kodak Company, Rochester, NY, USA).
The National Institutes of Health Image program was used to quantify the intensity of the resulting bands.

MTT assay. In total, $2 \times 10^{3} \mathrm{HeLa}$ cells (mock, control and C27) were seeded in a 96-well plate $24 \mathrm{~h}$ after transfection. After $12 \mathrm{~h}$, the cells were treated with different concentrations (in $\mu \mathrm{g} / \mathrm{ml}$ ) of 5 -FU of $0,10,20,30,40$ or 50 , respectively. The MTT assay was then performed at 12, 24, 48 and $72 \mathrm{~h}$ after 5-FU treatment. Briefly, $20 \mu \mathrm{l}$ of $5 \mathrm{mg} / \mathrm{ml}$ MTT (Sigma, St. Louis, MO, USA) in PBS was added and the cells were incubated for $4 \mathrm{~h}$ at $37^{\circ} \mathrm{C}$ with $5 \% \mathrm{CO}_{2}$. The cells were washed twice with PBS and the pellet was then solubilized in $150 \mu \mathrm{l}$ of $100 \%$ dimethylsulfoxide (Sigma) by agitating for 5 mins. The absorbance was measured on a microplate reader (Bio-Rad, Hercules, CA, USA) at a wavelength of $570 \mathrm{~nm}$. The rate of cell viability was calculated according to the equation: $\mathrm{A}_{570}(\mathrm{Cd}) / \mathrm{A}_{570}\left(\mathrm{C}_{0}\right) \times 100$.

$\mathrm{A}_{570}\left(\mathrm{C}_{0}\right)$ is the absorbance of the HeLa cells (mock, control and $\mathrm{C} 27$ ) without 5-FU treatment and $\mathrm{A}_{570}(\mathrm{Cd})$ is the absorbance of the cells exposed to the different concentrations of 5-FU. All the experiments were performed in triplicate.

Colony formation assay. Twelve hours after transfection, control-HeLa and C27-HeLa cells were exposed to $20 \mu \mathrm{g} / \mathrm{ml}$ 5-FU, known as the 5-FU and C27+5-FU groups, respectively. The control-HeLa cells were exposed to PBS as a control, designated as the group control. After $12 \mathrm{~h}$, the medium containing 5-FU was replaced. The cells were allowed to grow for 10 days, fixed with methanol for $10 \mathrm{~min}$ and stained with Giemsa for $15 \mathrm{~min}$. The plates were washed and dried, and the colonies were counted. The experiments were performed in triplicate.

Flow cytometric analysis of apoptosis. For a quantitative analysis of apoptosis, the cells were harvested $48 \mathrm{~h}$ after treatment with $20 \mu \mathrm{g} / \mathrm{ml} 5-\mathrm{FU}$, washed once in ice-cold PBS, incubated with annexin V-FITC/PI (Boehringer, Mannheim, Germany) in calcium containing HEPES (Sigma) buffer, and then immediately analyzed with a flow cytometry machine (Becton-Dickinson, Bedford, MA, USA).

Terminal deoxynucleotidyl transferase-mediated dUTP nick-end labeling (TUNEL) assay. The presence of apoptotic cells in the HeLa cells was detected by the TUNEL assay using the in situ cell death detection kit (POD; Roche Diagnostics, Mannheim, Germany) according to the manufacturer's instructions. The apoptotic cells were analyzed under a fluorescence microscope (Olympus Corporation, Tokyo, Japan).

Statistical analysis. Data were presented as the mean \pm SD. The results were compared by two-way analysis of variance. All the statistical calculations were performed with the SPSS11.0 software package (SPSS, Inc., Chicago, IL, USA). P<0.05 was used to indicate a statistically significant difference.

\section{Results}

hTERTC27 expression in HeLa cells following transfection. Exogenous hTERTC27 protein was detected by western blot analysis at 12, 24, 48 and $72 \mathrm{~h}$ after transfection. As shown 
A

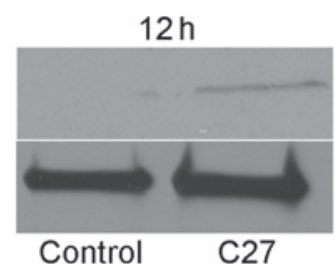

B

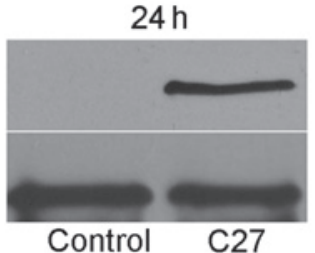

C

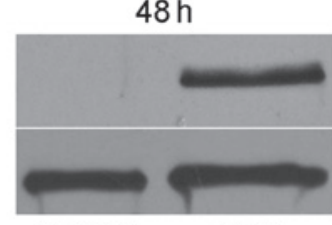

Control
D

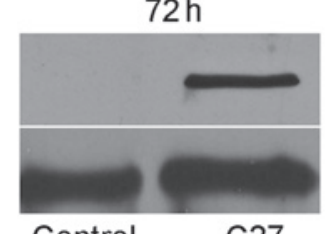

Figure 1. hTERTC27 overexpression in HeLa cells following transfection. The HeLa cells were transfected with pcDNA3.1-hTERTC27 plasmid and 12, 24, 48 and $72 \mathrm{~h}$ later, western blot analysis was used to observe the expression of the hTERTC27 using corresponding antibodies against the hTERT $\mathrm{COOH}$-terminal polypeptide. Actin was probed with anti-actin antibody as a loading control. (A) hTERTC27 expression $12 \mathrm{~h}$ after transfection; (B) hTERTC27 expression $24 \mathrm{~h}$ after transfection; (C) hTERTC27 expression $48 \mathrm{~h}$ after transfection; and (D) hTERTC27 expression $72 \mathrm{~h}$ after transfection.. hTERTC27, human telomerase reverse transcriptase C27.

in Fig. 1A, the cells transfected with a recombinant plasmid containing hTERTC27 cDNA expressed hTERTC27 protein $(27 \mathrm{kDa})$ slightly $12 \mathrm{~h}$ after transfection. After $24 \mathrm{~h}$, the cells expressed the hTERTC27 protein in abundance. However, no exogenous hTERTC27 protein was detected in the non-transfected HeLa cells, and empty vector-transfected cells. Thus, the cells were treated with 5-FU $24 \mathrm{~h}$ following transfection in the subsequent experiments.

hTERTC27 enhances HeLa cell sensitivity to 5-FU treatment. The effect of overexpressed hTERTC27 polypeptide on cell viability following treatment with different concentrations of 5-FU was determined at indicated time points by the MTT assay. As shown in Fig. 2, the cell viability was markedly inhibited in the $\mathrm{C} 27$ group when compared with that in the mock group $(\mathrm{P}<0.01)$ and control $(\mathrm{P}<0.01)$. However, no significant difference was observed between the mock group and the control $(\mathrm{P}>0.01)$. These results suggested that overexpressed hTERTC27 enhances the sensitivity of HeLa cells to 5-FU treatment and promotes 5-FU-induced growth inhibition. In order to perform subsequent experiments, a final concentration of $20 \mu \mathrm{g} / \mathrm{ml} \mathrm{5-FU} \mathrm{was} \mathrm{selected} \mathrm{to} \mathrm{observe} \mathrm{the}$ effects of overexpressed hTERTC27 and 5-FU on HeLa cell proliferation and apoptosis.

hTERTC27 promotes inhibition of proliferation of HeLa cells with 5-FU treatment. The control-HeLa and C27-HeLa cells were exposed to $20 \mu \mathrm{g} / \mathrm{ml} 5$-FU (5-FU and $\mathrm{C} 27+5$-FU groups), and control-HeLa cells were exposed to PBS as a control (control group). As shown in Fig. 3A, the cell numbers were significantly decreased in the $\mathrm{C} 27+5-\mathrm{FU}(\mathrm{P}<0.01)$ and $5-\mathrm{FU}(\mathrm{P}<0.01)$ groups when compared with that in the control group. Notably, the $\mathrm{C} 27+5-\mathrm{FU}$ group demonstrated a lower cell proliferation rate compared with that of the 5-FU group $(\mathrm{P}<0.01)$. A colony formation assay revealed that the colony formation rates in the 5 -FU $(2.63 \pm 0.58 \%)$ and $\mathrm{C} 27+5-\mathrm{FU}(0.32 \pm 0.09 \%)$ groups

A

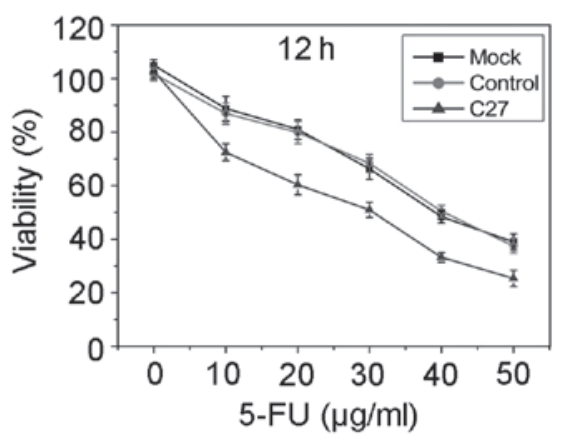

B

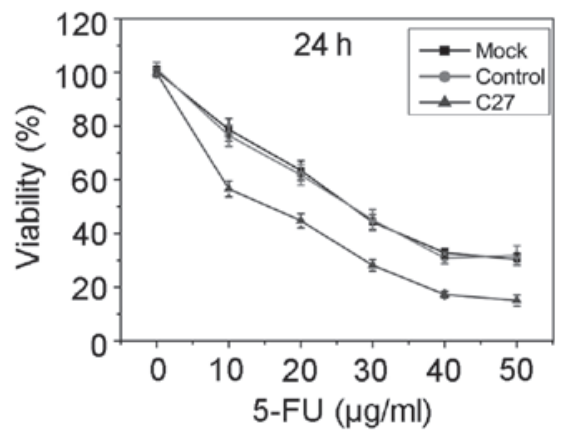

C

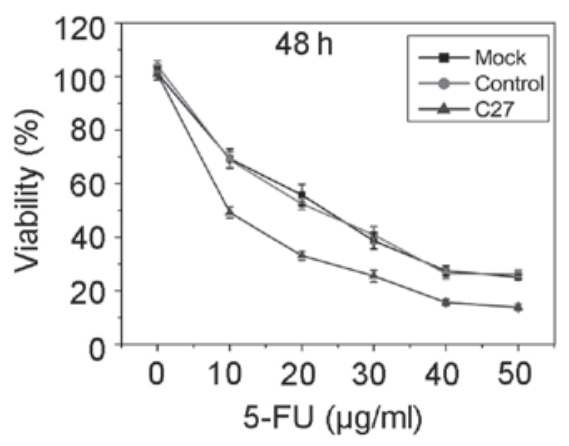

D

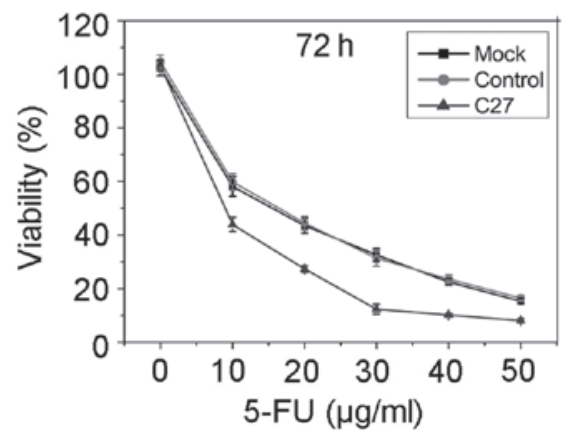

Figure 2. hTERTC27 enhances HeLa cell sensitivity to 5-FU. HeLa cells transfected with the pcDNA3.1 vector or pcDNA3.1-hTERTC27 plasmid were seeded into 96-well plates. After $12 \mathrm{~h}$, the cells were treated with the indicated concentrations of 5-FU. The inhibitory rate was measured by an MTT assay at the indicated time points following treatment: (A) $12 \mathrm{~h}$, (B) $24 \mathrm{~h}$, (C) $48 \mathrm{~h}$ and (D) $72 \mathrm{~h}$. hTERT C27, human telomerase reverse transcriptase C27; 5-FU, 5-fluorouracil.

were significantly lower compared with that in the control $(68.74 \pm 8.62 \%)$ group $(\mathrm{P}<0.05)$ (Fig. 3B and $\mathrm{C})$. Moreover, the combined therapeutic group of $\mathrm{C} 27+5-\mathrm{FU}(0.3 \pm 0.1 \%)$ demonstrated an additional decrease in the colony formation rate when compared with the 5-FU group alone. These results indicate that overexpressed hTERTC27 evidently inhibits the proliferation and colony formation in HeLa cells with 5-FU treatment. 
A

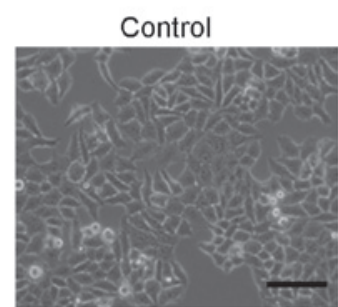

B

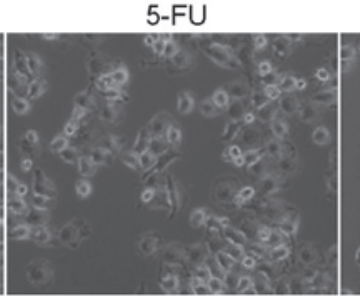

(a)

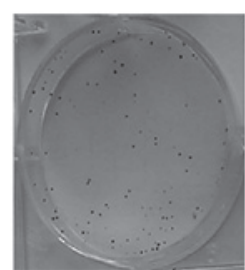

Control

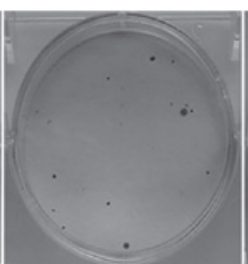

5-FU

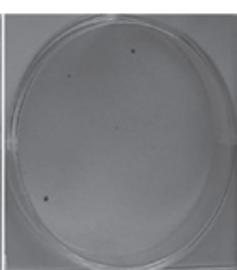

$5-\mathrm{FU}+\mathrm{C} 27$
$5-\mathrm{FU}+\mathrm{C} 27$

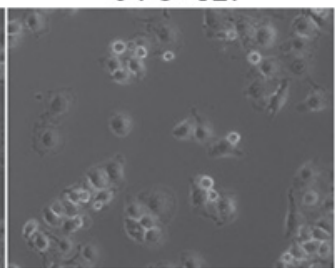

C

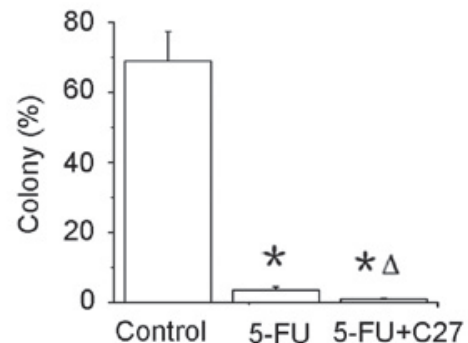

Figure 3. hTERTC27 enhances growth inhibition of HeLa cells with 5-FU treatment. (A) HeLa cells transfected with pcDNA3.1 vector or pcDNA3.1hTERTC27 plasmid were treated with $20 \mu \mathrm{g} / \mathrm{ml}$ 5-FU for $48 \mathrm{~h}$. The changes in cell morphology and cell number were observed microscopically. (B) Colony formation assay. Representative pictures of the visible colonies. (C) Colony numbers were counted. The values are the mean $\pm \mathrm{SD}, \mathrm{n}=6$; ${ }^{*} \mathrm{P}<0.01 \mathrm{vs}$. control and ${ }^{\Delta} \mathrm{P}<0.05$ vs. group 5-FU. hTERT, human telomerase reverse transcriptase; 5-FU, 5-fluorouracil.

A

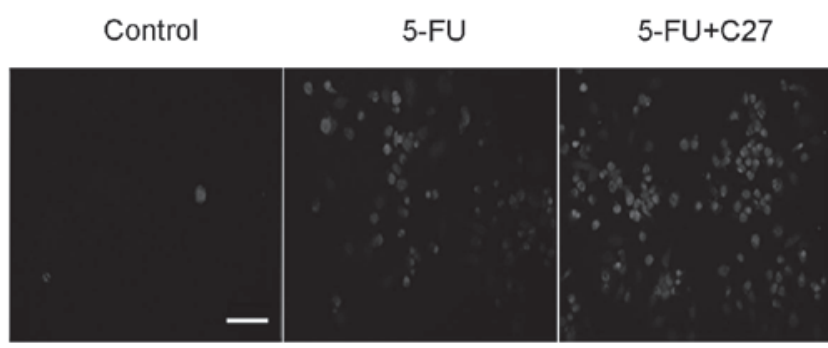

C

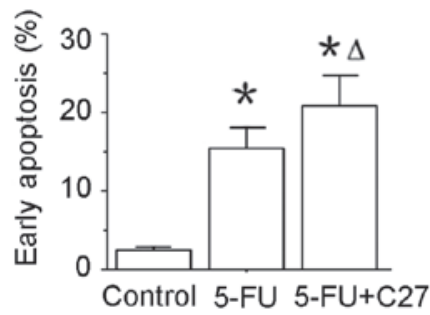

D

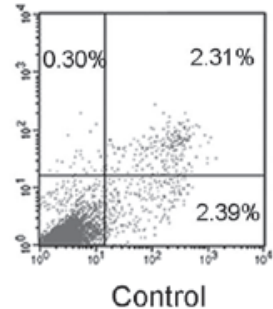

B

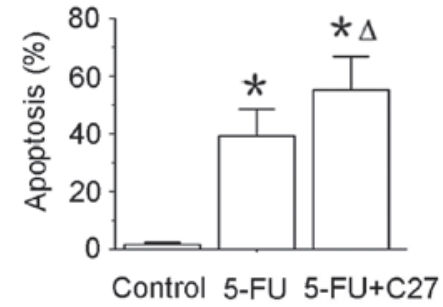

Figure 4. hTERTC27 promotes apoptosis of HeLa cells with 5-FU treatment. Cells transfected with the pcDNA3.1 vector or pcDNA3.1-hTERTC27 plasmid were treated with $20 \mu \mathrm{g} / \mathrm{ml} 5$-FU for $48 \mathrm{~h}$. The TUNEL assay. (A) Representative fields of the TUNEL assay, scale bar, $2 \mathrm{~mm}$. (B) TUNEL positive cells were counted. The values are the mean $\pm \mathrm{SD}, \mathrm{n}=6$; ${ }^{*} \mathrm{P}<0.01$ vs. control and ${ }^{\mathrm{P}} \mathrm{P}<0.05$ vs. group 5 -FU. (C and D) Apoptosis was determined using an annexin V-PI double-staining flow cytometric technique. The annexin $\mathrm{V}^{+} / \mathrm{PI}^{-}$cells were counted by flow cytometric analysis during early apoptosis. The values are the mean $\pm \mathrm{SD}, \mathrm{n}=3$; ${ }^{*} \mathrm{P}<0.01$ vs. control and ${ }^{\wedge} \mathrm{P}<0.05$ vs. group 5-FU. hTERT, human telomerase reverse transcriptase; 5-FU, 5-fluorouracil.

hTERTC27 promotes apoptosis of HeLa cells with 5-FU treatment. To determine whether hTERTC27 promotes apoptosis of HeLa cells, the TUNEL assay and annexin-V/PI double staining followed by a flow cytometry assay were performed. The apoptotic death (TUNEL positive) of the 5-FU group $(39.28 \pm 9.25 \%)$ was highly increased compared with that of the control group $(1.66 \pm 0.34 \%$; $(\mathrm{P}<0.01)$. In addition, the combinatorial group of $\mathrm{C} 27+5-\mathrm{FU}(55.14 \pm 11.67 \%)$ revealed a further increase in the TUNEL-positive rate when compared with the 5-FU group $(\mathrm{P}<0.05)$. To confirm this result, early apoptosis (annexin- $\mathrm{V}^{+} / \mathrm{PI}$ ) was assessed by flow cytometry
(Fig. 4C and D). Additionally, 23\% HeLa cells in group $\mathrm{C} 27+5-\mathrm{FU}$ were found to undergo early apoptosis, while only $\sim 15 \%$ in the 5 -FU and $2 \%$ in the control groups. These data indicate that hTERTC27 overexpression may promote the HeLa cell apoptosis induced by 5 -FU.

hTERTC27 promotes the activation of caspases and the downregulation of Bcl-2 in HeLa cells with 5-FU treatment. Apoptosis is known to be characterized by the activation of caspases. Thus, the effect of hTERTC27 and 5-FU was examined on the activation of caspase-3 and -9. As shown in Fig. 5, 
A
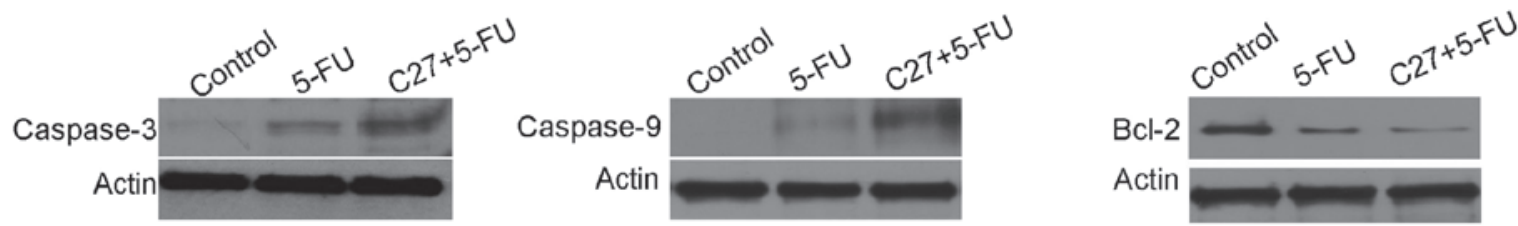

B
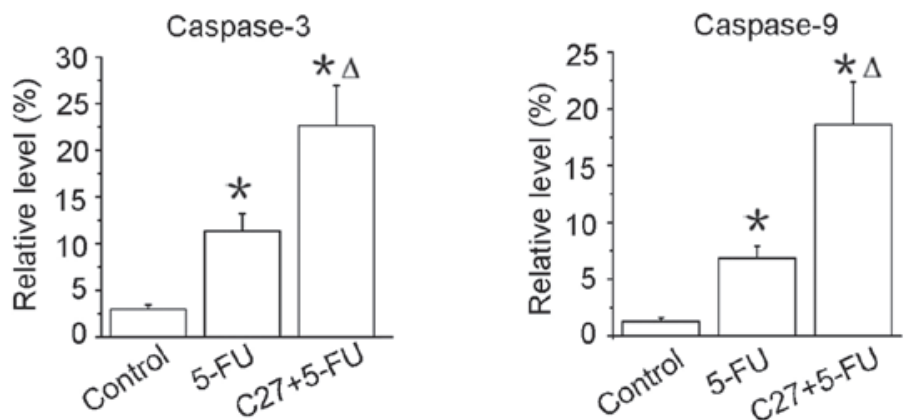

$\mathrm{Bcl}-2$

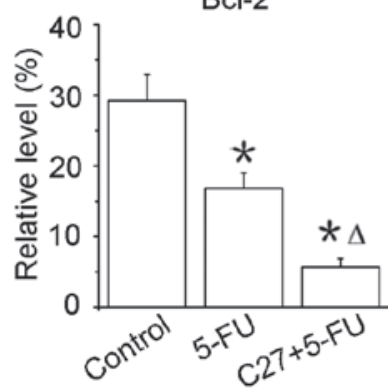

Figure 5. Western blot analysis of cleaved caspase-3, -9 and Bcl-2 protein. (A) The expression of caspase-3, -9 and Bcl-2 in HeLa cells following treatment Actin was used and probed as a loading control. (B) Quantification of caspase- $-3,-9$ and Bcl-2. The values are the mean $\pm \mathrm{SD}, \mathrm{n}=3$; ${ }^{*} \mathrm{P}<0.01$ vs. control and ${ }^{\wedge} \mathrm{P}<0.05$ vs. group 5-FU. Bcl2, B-cell lymphoma 2; 5-FU, 5-fluorouracil.

the amount of caspase-3 activation was evidently enhanced in the $\mathrm{C} 27+5-\mathrm{FU}$ group when compared with that in the $5-\mathrm{FU}$ group $(\mathrm{P}<0.01)$. Similar results were also observed in the activation of caspase-9. The changes in the signalling proteins were evaluated to be relevant to apoptosis. Bcl-2 is one of the most significant proteins of the antiapoptotic family. As shown in Fig. 5, the Bcl-2 expression was markedly reduced in the $\mathrm{C} 27+5-\mathrm{FU}$ group when compared with that in the 5-FU group $(\mathrm{P}<0.01)$. These results consistently demonstrated that the overexpression of hTERTC27 clearly promoted 5-FU-induced apoptotic death in HeLa cells.

\section{Discussion}

In the present study, the overexpression of exogenous hTERTC27 was revealed to contribute to sensitizing HeLa cells to chemotherapeutic drugs such as 5-FU by promoting apoptosis. 5-FU, as an antimetabolic drug, is widely used in cancer chemotherapy due to its easy administration and high efficiency $(3,18)$. However, long-term 5-FU chemotherapy is usually not administered to patients due to a decreasing sensitivity and side effects caused by the high dosage. Therefore, enhancing the sensitivity of cancer cells to 5-FU has become a crucial strategy for enhancing the antitumor effect of chemotherapeutic agents.

A number of therapeutic approaches are currently being explored to target telomere or telomerase for cancer therapy since telomerase is highly expressed in the majority of the tumors $(11,19)$. The abnormal telomerase activity protects telomere from being shortened and therefore leads to uncontrollable cell proliferation ability and malignant transformation (10). In our previous study, the ectopic expression of hTERTC27 was reported to lead to chromosome end-to-end fusion during anaphase and telomere dysfunction (13). In the present study, hTERTC27 overexpression was demonstrated to increase the sensitivity of HeLa cells to 5-FU treatment by significantly inhibiting the cell viability. These changes resulted from the hTERTC27-induced increasing sensitivity of HeLa cells to the oxidative stress caused by 5-FU, which is consistent with the results of previous studies in which the overexpression of this polypeptide was observed to markedly enhance the sensitivity of HeLa cells to $\mathrm{H}_{2} \mathrm{O}_{2}$-induced injury (14). These results indicated that a low concentration of 5-FU treatment in the presence of hTERTC27 may achieve the same therapeutic effect as a higher 5-FU concentration. This combinatorial strategy may decrease the therapeutic dose of 5-FU, and thus reduce the side effects of 5-FU chemotherapy.

The Bcl-2 family proteins are key regulators of cell apoptosis $(20,21)$, and sequential activation of caspases has been revealed to be involved in cell apoptosis (22). The activation of the caspase- 3 pathway is a hallmark of apoptosis, and is activated in the apoptotic cell by extrinsic (death ligand) and intrinsic (mitochondrial) pathways (23). Caspase-9, an initiator caspase, has been connected to the mitochondrial death pathway (24). Once initiated, caspase-9 continues to cleave procaspase-3, leading to multiple cellular target cleavage including poly-ADP ribose polymerase (25). In the present study it was found that 5-FU in combination with hTERTC27 significantly downregulated the expression of Bcl-2 and markedly promoted the activation of caspase- 3 and -9 , which confirmed that overexpression of the hTERTC27 polypeptide may enhance the antitumor effects of 5-FU by promoting cell apoptosis.

In conclusion, to the best of our knowledge, the present study reports for the first time the anticancer potential of the combination of 5-FU treatment and hTERTC27 overexpression. The overexpression of hTERTC27 was revealed to increase the sensitivity of cancer cells to 5-FU treatment. Furthermore, the combinatorial therapy was demonstrated to promote 5-FU-induced activation of caspase-3 and -9, and downregulate the expression levels of $\mathrm{Bcl}-2$. Altogether, the present study has shown that the combination of 5-FU treatment and hTERTC27 overexpression may provide a potential 
clinical strategy for enhancing the sensitivity of tumor cells to chemotherapy.

\section{Acknowledgements}

This study was supported by grants from National Natural Science Foundation of China (NSFC; 81301318), Science and Technology Project of Guangdong (2011B031800351), Shenzhen Basic Research Project (JCYJ20120613170218654), and the Natural Science Foundation of SZU (80100035901).

\section{References}

1. Markman M: Chemoradiation in the management of cervix cancer: current status and future directions. Oncology 84: 246-250, 2013.

2. Hemaiswarya S and Doble M: Combination of phenylpropanoids with 5-fluorouracil as anti-cancer agents against human cervical cancer (HeLa) cell line. Phytomedicine 20: 151-158, 2013.

3. Yamamoto K, Fujiwara Y, Nishida T, et al: Induction chemotherapy with docetaxel, 5-FU and CDDP (DFP) for advanced gastric cancer. Anticancer Res 29: 4211-4215, 2009.

4. Osaka Y, Shinohara M, Hoshino S, Ogata T, Takagi Y, Tsuchida A and Aoki T: Phase II study of combined chemotherapy with docetaxel, CDDP and 5-FU for highly advanced esophageal cancer. Anticancer Res 31: 633-638, 2011.

5. Nagata M, Nakayama H, Tanaka T, et al: Overexpression of cIAP2 contributes to 5-FU resistance and a poor prognosis in oral squamous cell carcinoma. Br J Cancer 105: 1322-1330, 2011.

6. Wang CJ, Stratmann J, Zhou ZG and Sun XF: Suppression of microRNA-31 increases sensitivity to 5-FU at an early stage, and affects cell migration and invasion in HCT-116 colon cancer cells. BMC Cancer 10: 616, 2010.

7. Karasawa H, Miura K, Fujibuchi W, et al: Down-regulation of cIAP2 enhances 5-FU sensitivity through the apoptotic pathway in human colon cancer cells. Cancer Sci 100: 903-913, 2009.

8. Lin G, Lin MC, Lin S, et al: Early growth response protein-1 promoter-mediated synergistic antitumor effect of hTERTC27 gene therapy and 5-fluorouracil on nasopharyngeal carcinoma. Cancer Biother Radiopharm 27: 434-441, 2012.

9. Gomez DE, Armando RG, Farina HG, Menna PL, Cerrudo CS, Ghiringhelli PD and Alonso DF: Telomere structure and telomerase in health and disease (Review). Int J Oncol 41: $1561-1569,2012$.

10. Shay JW and Wright WE: Role of telomeres and telomerase in cancer. Semin Cancer Biol 21: 349-353, 2011.
11. Ruden $M$ and Puri N: Novel anticancer therapeutics targeting telomerase. Cancer Treat Rev 39: 444-456, 2013.

12. Podlevsky JD and Chen JJ: It all comes together at the ends: telomerase structure, function, and biogenesis. Mutat Res 730: 3-11, 2012.

13. Huang JJ, Lin MC, Bai YX, et al: Ectopic expression of a $\mathrm{COOH}$-terminal fragment of the human telomerase reverse transcriptase leads to telomere dysfunction and reduction of growth and tumorigenicity in HeLa cells. Cancer Res 62: 3226-3232, 2002.

14. Huang J, Bai YX, Han SW, et al: A human TERT C-terminal polypeptide sensitizes HeLa cells to $\mathrm{H}_{2} \mathrm{O}_{2}$-induced senescence without affecting telomerase enzymatic activity. Biochem Biophys Res Commun 301: 627-632, 2003.

15. Ng SS, Gao Y, Chau DH, et al: A novel glioblastoma cancer gene therapy using AAV-mediated long-term expression of human TERT C-terminal polypeptide. Cancer Gene Ther 14: 561-572, 2007.

16. Gao Y, Ng SS, Chau DH, et al: Development of recombinant adeno-associated virus and adenovirus cocktail system for efficient hTERTC27 polypeptide-mediated cancer gene therapy. Cancer Gene Ther 15: 723-732, 2008.

17. Lin G, Zhao L, Yin F, et al: TCF3 inhibits F9 embryonal carcinoma growth by the down-regulation of Oct4. Oncol Rep 26: 893-899, 2011.

18. Afzal S, Jensen SA, Vainer B, et al: MTHFR polymorphisms and 5-FU-based adjuvant chemotherapy in colorectal cancer. Ann Oncol 20: 1660-1666, 2009 .

19. Lü MH, Liao ZL, Zhao XY, et al: hTERT-based therapy: A universal anticancer approach (Review). Oncol Rep 28: 1945-1952, 2012.

20. Elmore S: Apoptosis: a review of programmed cell death. Toxicol Pathol 35: 495-516, 2007.

21. García-Sáez AJ: The secrets of the Bcl-2 family. Cell Death Differ 19: 1733-1740, 2012.

22. Ola MS, Nawaz M and Ahsan $\mathrm{H}$ : Role of Bcl-2 family proteins and caspases in the regulation of apoptosis. Mol Cell Biochem 351: 41-58, 2011.

23. Porter AG and Jänicke RU: Emerging roles of caspase-3 in apoptosis. Cell Death Differ 6: 99-104, 1999.

24. Würstle ML, Laussmann MA and Rehm M: The central role of initiator caspase-9 in apoptosis signal transduction and the regulation of its activation and activity on the apoptosome. Exp Cell Res 318: 1213-1220, 2012

25. Rosen A and Casciola-Rosen L: Macromolecular substrates for the ICE-like proteases during apoptosis. J Cell Biochem 64: 50-54, 1997. 